\title{
Propuestas Metodológicas para Trabajo Social en Intervención social y sistematización*
}

\section{Patricia Castañeda}

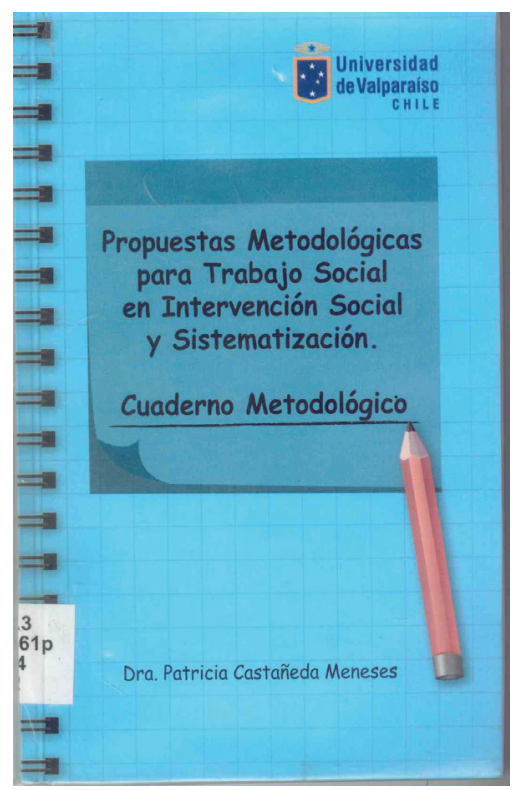

\section{Cecilia Ponce-Rebolledo*}

Cada profesión tiene sus características, su sello y sus formas de proceder en relación a su quehacer y ante determinadas situaciones. De esta forma, la presente reseña analiza metodologías de trabajo propuestas por la autora y da cuenta, además, cómo el trabajo social crece, evoluciona y se mantiene vigente; esto, desde una mirada crítica y autocrítica que

** Facultad de ciencias de la salud, Universidad San Sebastián, Lientur 1457, Concepción 4080871, 
permite desafiar lo tradicional y observar posibles rutas para la profesión. Patricia Castañeda Meneses, desde su rol de académica e investigadora en la Escuela de Trabajo Social de la Universidad de Valparaíso, hace aportes reconocidos y concretos al trabajo social, y a otras profesiones afines, lo cual cobra vital importancia si consideramos nuestra realidad y la compleja cuestión social imperante.

Desde el contexto histórico, es necesario esbozar que en los años previos e inmediatamente posteriores al Golpe de Estado, nuestro país fue intervenido económica y políticamente por Norteamérica: se conocen acciones encubiertas de los Estados Unidos para influir en la política chilena, continuando así con el sistema imperialista. Esta influencia extranjera y su combinación perfecta con las Fuerzas Armadas de Chile originan el Golpe de Estado chileno, y aunque no es este el tema de esta reseña, es necesario mencionarlo para contextualizar cómo este periodo de dictadura, censura y persecución obliga al trabajo social a buscar la sobrevida, tanto en contextos universitarios como laborales, y aun así mantener su compromiso con los sectores vulnerables de la sociedad.

Castañeda, menciona que la formación tradicional del trabajador social profesional organizaba sus procesos de enseñanza en torno a la intervención en caso, grupos y comunidad. Sin embargo, los cambios económicos de entonces y la polarización política imperante dan inicio a un cuestionamiento no menor de la profesión. Lo que se conoce como re-conceptualización, da cuenta de la necesidad de contar con un método único y diferenciador. Para avanzar en la creación de este método se deben tomar decisiones en medio de la contingencia; estas decisiones tuvieron que ver con conceptualizaciones de las ciencias sociales, la investigación cuantitativa y la planificación social, utilizando estos elementos como estrategias de blindaje profesional. Con ello, posteriormente, se propone el ciclo tecnológico, que incluye investigación, programación, ejecución y evaluación, alineándose a la corriente tecnológica-metodológica que integra teoría y práctica. Es así como se va conformando este método único que pudiera aplicarse a diferentes situaciones, incorporándose también ciertos conceptos como la de racionalidad, la existencia de un medio y un fin, y la de causa y efecto.

Según menciona la autora, esta fue la impronta metodológica y tecnocrática, basada en modelos teóricos, que se transmitió generacionalmente durante los 17 años de dictadura. Paralelo a esto, el Estado disminuye su presencia en distintas áreas sociales y económicas, 
con lo que baja la demanda de trabajadores sociales, manteniéndose sí las intervenciones de caso social, asociadas a asistencialdad, avaladas por el manejo histórico que la profesión tiene de ella. Surge, por otro lado, el ejercicio profesional en instancias no gubernamentales ligadas a la contención y reparación de las víctimas de violaciones a los derechos humanos. Aquí se pudo continuar con el trabajo de grupo y comunidad.

Por su parte, las Escuelas de Trabajo Social de la Universidad de Chile y de la Universidad Católica, respectivamente, revisan los antecedentes de la génesis del ciclo tecnológico, ambos trabajos convergen en que el modelo tecnológico socializado en las escuelas configuraría una lógica de trabajo universal, aplicable a la totalidad y variabilidad de contextos, esto según lo mencionado en el libro.

La autora menciona que, a pesar de la realidad formativa, en relación al método único existen tensiones que, a lo menos, cuestionan la aplicabilidad de este método para distintas situaciones. Algunas de las tensiones tienen relación, por ejemplo, con la superposición e intersección de contenidos en las distintas casas formadoras, lo que confunde los límites e implicancias de la profesión y dominio profesional. Por otro lado, los estudios de post título y post grado en trabajo social han cuestionado la impronta tecnológica, flexibilizando y ampliando las fronteras profesionales, realizando ajustes, correcciones y resignificaciones metodológicas, reconociendo vulnerabilidades y también fortalezas del ciclo tecnológico. Además, con los procesos de innovación curricular se han incorporado enfoques complementarios. Por último, la consideración del ciclo tecnológico como único y distintivo resulta ambicioso, más aun considerando nuestra realidad social, donde el enfoque y el actuar deben relacionarse con conceptos como: diversidad, tolerancia e interculturalidad, cuyas demandas solo pueden ser flexibles.

Entonces, a modo de reflexión, por un lado existe esta lógica tecnocrática que se basa en la aplicación de las ciencias sociales para modificar realidades, cuyo rigor científico del diseño y sus procedimientos son impecables; y, por otro lado, se reconoce la dificultad, con este método, para enfrentar diferentes contingencias sociales, dado por la errónea concepción de universalidad de este ciclo tecnológico, que cierra el acceso a posibles oportunidades e innovación.

Entonces, se comparten plenamente las tensiones que menciona la autora en torno a la universalidad del ciclo tecnológico, así como 
la consideración de distintivo de la profesión, dado que, conceptos similares como diagnóstico, programación, ejecución y evaluación se usan también en otras disciplinas. Por lo que no pueden ser distintivos del trabajo social. Por otro lado, tratar temas como la intervención social $-y$ todo lo que involucra la interacción con personas, como sujetos de intervención- requiere de profesionales flexibles, creativos, con capacidad de reacción frente a las diversas demandas sociales existentes. Hoy menos que nunca podría un método ser universal, dado que las problemáticas sociales han cambiado, su multicausalidad ha cambiado, los actores sociales han cambiado, por lo que las metodologías y a la vez los modelos de intervención han evolucionado también. La especialización continua de los profesionales da cuenta también de cambio, evolución y no estancamiento. Por lo que un método rígido y lineal no puede ser flexible ante la diversidad, precisamente porque deja fuera de él temáticas emergentes no tradicionales. Castañeda nos ofrece un documento crítico, objetivo, libre de juicios de valor, a pesar de estar involucrada profesionalmente en él. Sin embargo, es necesario también apuntar que el formato posee características como letra pequeña, hojas cuadriculadas, tipo cuaderno de notas, que dificultan su lectura. 